\title{
(C) OPEN ACCESS \\ EUS-guided fine needle biopsy of pancreatic masses can yield true histology
}

\author{
Ji Young Bang, Shantel Hebert-Magee, Udayakumar Navaneethan, \\ Muhammad K Hasan, Robert Hawes, Shyam Varadarajulu
}

- Additional material is published online only. To view please visit the journal online (http://dx.doi.org/10.1136/ gutjnl-2017-315154).

Center for Interventional Endoscopy, Florida Hospital, Orlando, Florida, USA

\section{Correspondence to}

Dr Shyam Varadarajulu, Center for Interventional Endoscopy, Florida Hospital, Orlando, Florida, FL 32803, USA; svaradarajulu@yahoo.com

Received 28 August 2017 Revised 12 September 2017 Accepted 19 September 2017

Published Online First

7 October 2017

Check for updates

To cite: Bang JY, Hebert-

Magee S, Navaneethan U,

et al. Gut

2018:67:2081-2084.

\section{MESSAGE}

As cytological aspirates from endoscopic-ultrasound-guided fine needle aspiration (EUS-FNA) has limited diagnostic sensitivity and are suboptimal for molecular profiling and morphological characterisation of certain neoplasms, a fine needle biopsy (FNB) with three-pronged (Franseen geometry) cutting edge has been developed to procure histology. In a randomised trial of 46 patients with pancreatic masses, procurement of histological core tissue as evidenced by total tissue and tumour areas was significantly higher for 22G FNB than FNA needle. Also, retention of tissue architecture and presence of desmoplastic fibrosis, which are critical for ancillary testing and molecular profiling, respectively, were significantly higher for FNB.

\section{IN MORE DETAIL}

Given the poor outcomes of traditional chemotherapy, there is increased focus on molecular profiling so that pancreatic cancer treatment can be personalised. Pancreatic tissue with architecture containing both tumour cells and desmoplastic stroma is pivotal for molecular analysis. Although EUS-FNA is diagnostically accurate, the cytological aspirate is suboptimal for DNA sequencing. ${ }^{1-3}$ Therefore, clinical trials evaluating personalised treatment in pancreatic cancer prefer tissue procurement via percutaneous or surgical biopsies over EUS-FNA. ${ }^{4}$ Recently, a three-plane symmetric needle with Franseen geometry has been developed for performing EUS-guided FNB. ${ }^{5}$ The large crown-tip with three cutting edges and long insertion length were postulated to facilitate histological tissue procurement (figure 1A). We conducted a randomised trial comparing tissue acquisition between the 22-gauge (G) Franseen biopsy (Acquire, Boston Scientific) and 22G standard bevel FNA (Expect, Boston Scientific) (figure 1B) needles in patients undergoing EUS-guided sampling of pancreatic masses.

EUS-guided sampling was performed using both needle types, the 22G FNB and 22G FNA needles, with randomisation of the order in which the needles were used. After performing two dedicated passes for histological analysis by cell block using the randomised needle, two additional passes were made using the alternate needle. Main outcome was to compare median areas of total tissue and tumour, presence of desmoplastic fibrosis and retention of tissue architecture between the needle types. Secondary outcomes were to compare rates of diagnostic cell block and retention of tissue architecture. To limit subjectivity in interpretation, a specialised software (Nikon-NIS Elements Basic Research) was used for histological assessment to measure individual tissue components. Sample size was based on 90\% power and type I error rate $(\alpha)$ of 0.05 to detect $1 \mathrm{~mm}^{2}$ difference in mean procured core tissue area. Using SDs of 1.81 for FNB and 0.69 for FNA, based on a selection of previously obtained samples, ${ }^{5}$ sample size was estimated at 41 patients. Recruitment was set at 46 to account for $10 \%$ drop-out.

Forty-six of 71 screened patients were recruited for participation in the study (figure 2). The final diagnosis was pancreatic cancer in 37 , neuroendocrine tumour in 2 , sarcoma in 1 , small cell cancer in 1 and benign disease in 5 patients (online supplementary table 1$)$. Median area of total tissue $\left(6.1 \mathrm{~mm}^{2}\right.$ (IQR 2.2-9.9) vs $0.28 \mathrm{~mm}^{2}$ (IQR $0.045-$ $0.93), \mathrm{p}<0.0001)$, tumour $\left(0.68 \mathrm{~mm}^{2}\right.$ (IQR $0.23-$ $2.8)$ vs $0.099 \mathrm{~mm}^{2}$ (IQR $\left.0.004-0.30\right), \mathrm{p}<0.0001$ ), desmoplastic fibrosis $\left(3.9 \mathrm{~mm}^{2}\right.$ (IQR $\left.0.5-8.2\right)$ vs 0 (IQR 0-0.11), $\mathrm{p}<0.0001$ ), retained tissue architecture $(93.5 \%$ vs $19.6 \%, \mathrm{p}<0.0001)$ and cell block diagnostic yield $(97.8 \%$ vs $82.6 \% \mathrm{p}=0.03)$ were significantly higher for FNB (figure 3A-F, online supplementary tables 2 and 3 ).

Cell blocks from all 41 FNB specimens were conducive for immunohistochemistry (IHC) testing ( $\geq 10$ tumour cells/cell block section) compared with only 28 of 41 FNA specimens, $100 \%$ vs $68.3 \%$, $\mathrm{p}<0.0001$ (online supplementary table 2); specimens were not tested for IHC in five patients with benign disease. K-ras gene mutation testing was undertaken in FNB and FNA cell block specimens of five patients with pancreatic cancer (10 samples). Except for one FNB sample that contained extensive necrosis, G12D mutation was observed in two, G12A in one, G12V in three and wild-type and G12V mutations in three patients.

\section{COMMENTS}

The findings of our study prove that true histological samples can be obtained more reliably using the Franseen biopsy needle when compared with standard FNA needles. Although EUS-FNA is the technique of choice for tissue acquisition in pancreatic mass lesions, prior attempts at histological core tissue procurement were largely unsuccessful. Given the technical limitations with the use of Tru-cut biopsy needles and the lack of difference between the reverse bevel biopsy and standard FNA needles, a novel fork-tip needle (SharkCore, Medtronic) was recently developed to procure histology. In a retrospective study, the 


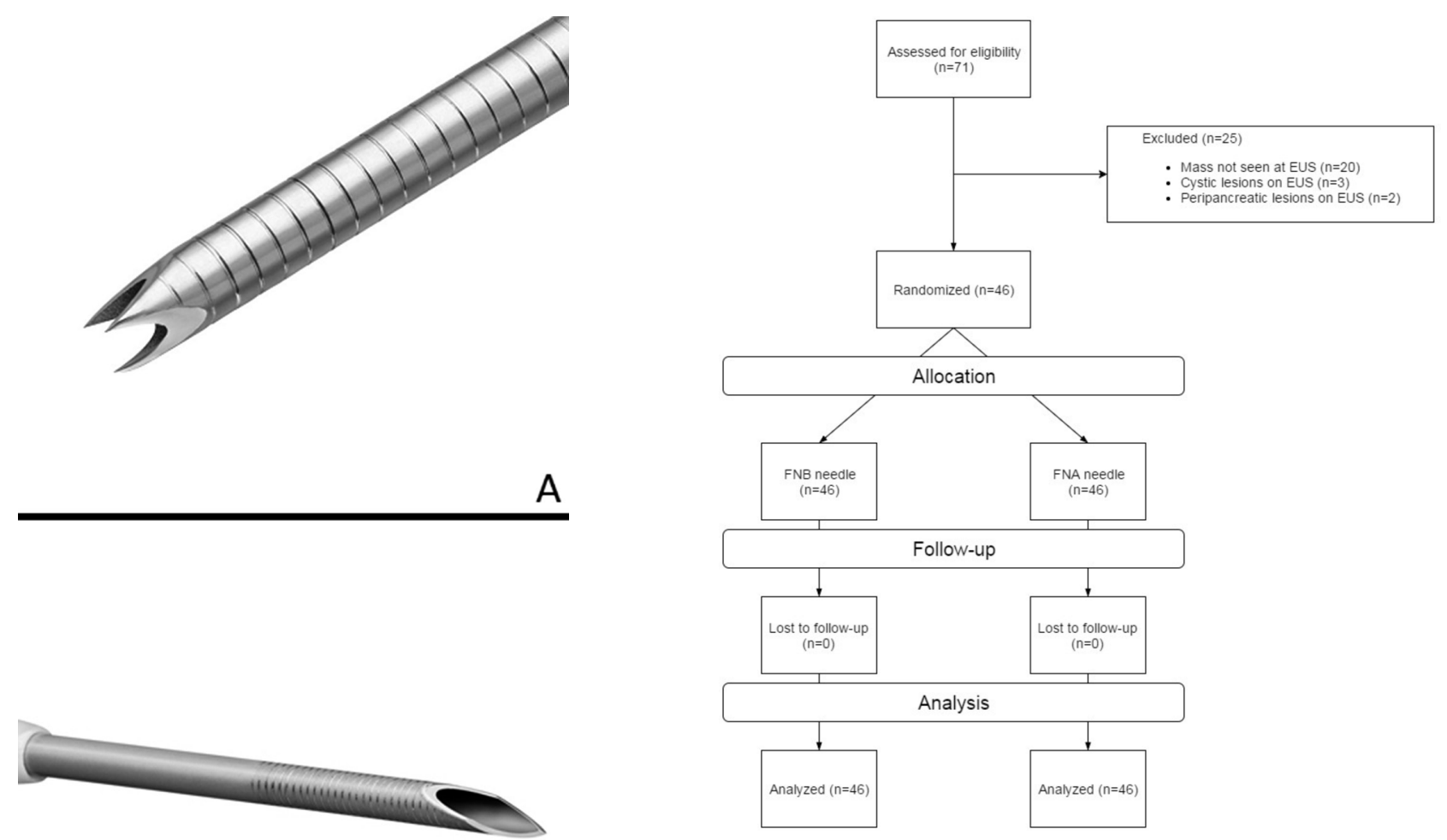

Figure 2 Flow diagram of patients recruited for participation in the randomised trial. FNA, fine needle aspiration; FNB, fine needle biopsy; EUS, endoscopic-ultrasound.

Figure 1 The 22G Franseen design with a crown-shaped needle tip revealing the three symmetrical planes for histological core tissue acquisition (A). The standard bevel needle used at fine needle aspiration for procurement of cytological aspirates (B).

fork-tip needle was found to yield significantly better cellularity, but specimen evaluation was both subjective and arbitrary based on a non-validated categorisation. ${ }^{6}$ The Franseen geometry incorporates a three-plane symmetry in which the inclination and included angles are constant, thereby providing the most optimal needle design for tissue penetration and cutting. ${ }^{7}$ This likely contributed to the superior performance of the new FNB needle.

In this study, in order to prove true histological tissue procurement, we used specialised imaging software to quantify individual tissue components. Our observations proved that the study hypothesis was correct: the Franseen biopsy needle yielded high-quality histology samples significantly more often than the standard FNA needle. Histological architecture was retained, and the total tissue and tumour yield from the FNB needles were 20 and 7 times greater, respectively, than that procured using FNA needles from the same lesion. Furthermore, desmoplastic fibrosis was seen in $85 \%$ of FNB samples compared with only $33 \%$ in the FNA cohort. Desmoplasia is an expected cellular reaction to a neoplastic process but is difficult to procure using standard bevel FNA needles as it requires 'coring' of the tissue. This is particularly relevant in clinical trials because patients with pancreatic cancer with activated stroma tend to have a poor prognosis and are less likely to benefit from neoadjuvant therapy. ${ }^{89}$ Two of the 10 samples in this study tested positive for K-ras G12D mutation, which is an independent prognostic marker for advanced ductal adenocarcinoma with poor response to gemcitabine-based chemotherapeutic regimens. ${ }^{10}$

How are the findings of this study relevant and why is it important? One, the ability to procure adequate volume of tissue using the Franseen biopsy needle enables the reliable performance of ancillary studies. Therefore, when a rare diagnosis is suspected or if the need for ancillary testing is anticipated, then EUS-guided tissue acquisition using an FNB needle can be specifically requested. Two, the diagnostic sensitivity of EUS is reliant on availability of a cytopathologist to render rapid onsite evaluation (ROSE). This limitation has confined the use of EUS to mostly major medical centres where ROSE is readily available. A common alternative technique is to prepare a cell block for offsite assessment. However, the diagnostic yield and accuracy of cell block using standard FNA needles is only $75 \%-80 \% .^{11} 12$ This is because the aspirate is oftentimes limited in cellularity and lacks desmoplastic stroma with aborted glands, which are both histological hallmarks of malignancy. The Franseen biopsy needle by the virtue of its ability to procure large volume of tumour cells and stromal fibrosis yields a better histological sample that enables the pathologist to render a diagnosis of neoplasia with relative ease. This was obvious from the high rates of diagnostic adequacy (>95\%) and accuracy (>90\%) that was achieved for cell block using the Franseen biopsy needle.

There are a few limitations to this study. First, the performance of the Franseen needle in evaluating lesions other than pancreatic masses is unclear. Second, although molecular biomarkers may be prognostically useful, their application outside of clinical trials is limited. Therefore, not all pancreatic masses require FNB sampling. Its use must be based on treatment protocols, laboratory standards and most importantly after discussion with medical and surgical oncologists at a given institution.

In conclusion, the Franseen biopsy needle enables acquisition of true histological core tissue under EUS guidance more successfully 


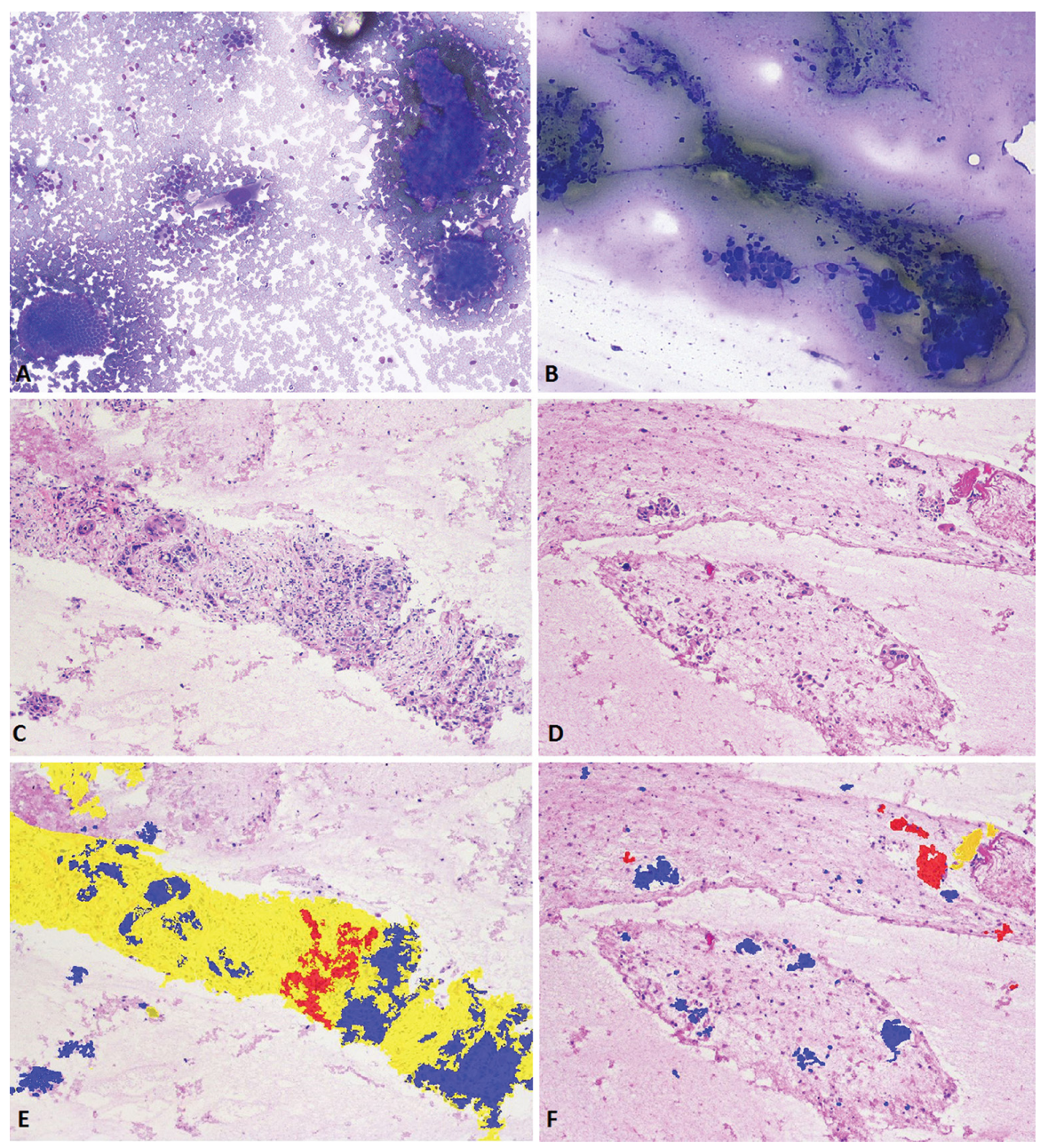

Figure 3 Rapid onsite evaluation of a pancreatic head mass biopsied using the Franseen needle reveals a cellular specimen comprising malignant cells, fibrosis and benign reactive ductal epithelium ( $\mathrm{A}$; Diff-Quik staining, 200x). The corresponding aspirate from a standard FNA needle reveals scattered malignant cells and with minimal fibrosis ( $B$; Diff-Quik staining, 100x). H\&E staining of pancreatic adenocarcinoma (100x) procured with the Franseen needle. Cores of exuberant dense desmoplastic fibrosis are seen entrapping malignant ductal epithelium and scattered benign residual acini on sections from the cell block (C). The corresponding image of a specimen from an FNA needle reveals minimal tumour cells and lack of any desmoplastic fibrosis (D). Digital image analysis reveals dense desmoplastic fibrosis (highlighted yellow) surrounding malignant (highlighted blue) ductal groups and foci of residual benign acini (E). The corresponding image of a specimen from an FNA needle reveals fewer tumour cells, lack of any significant architecture and a minute fragment of fibrosis (F). FNA, fine needle aspiration.

than the standard FNA needle. This development is likely to further advance the role of EUS in the oncological management of patients.

Contributors JYB: acquisition of data, endoscopist performing procedures in the trial, analysis and interpretation of data, statistical analysis, drafting of manuscript, critical revision of manuscript. SV: study concept and design, endoscopist performing procedures in the trial, drafting of manuscript, critical revision of manuscript. SH-M: pathologist involved in analysis and interpretation of cytology and cell block, drafting of manuscript, critical revision of manuscript. MKH, UN, RH: endoscopist performing procedures in the trial, critical revision of manuscript.

Competing interests SV: consultant for olympusm medical systems corporation and Boston scientific corporation. RH: consultant for olympus medical systems corporation and boston scientific corporation.

Ethics approval Institutional review board.

Provenance and peer review Not commissioned; internally peer reviewed.

Open access This is an open access article distributed in accordance with the Creative Commons Attribution Non Commercial (CC BY-NC 4.0) license, which permits others to distribute, remix, adapt, build upon this work non-commercially, and license their derivative works on different terms, provided the original work is properly cited and the use is non-commercial. See: http://creativecommons.org/ licenses/by-nc/4.0/

(c) Article author(s) (or their employer(s) unless otherwise stated in the text of the article) 2018. All rights reserved. No commercial use is permitted unless otherwise expressly granted.

\section{REFERENCES}

1 Chantrill LA, Nagrial AM, Watson C, et al. Precision medicine for advanced pancreas cancer: the individualized molecular pancreatic cancer therapy (IMPaCT) trial. Clin Cancer Res 2015;21:2029-37.

2 Varadarajulu S, Tamhane A, Eloubeidi MA. Yield of EUS-guided FNA of pancreatic masses in the presence or the absence of chronic pancreatitis. Gastrointest Endosc 2005;62:728-36.

3 Hébert-Magee S, Bae S, Varadarajulu S, et al. The presence of a cytopathologist increases the diagnostic accuracy of endoscopic ultrasound-guided fine needle aspiration cytology for pancreatic adenocarcinoma: a meta-analysis. Cytopathology 2013:24:159-71.

4 Hingorani SR, Harris WP, Beck JT, et al. Phase Ib Study of PEGylated Recombinant human hyaluronidase and gemcitabine in patients with advanced pancreatic cancer Clin Cancer Res 2016;22:2848-54.

5 Bang JY, Hebert-Magee S, Hasan MK, et al. Endoscopic ultrasonography-guided biopsy using a Franseen needle design: initial assessment. Dig Endosc 2017;29:338-46. 
6 Kandel P, Tranesh G, Nassar A, et al. EUS-guided fine needle biopsy sampling using a novel fork-tip needle: a case-control study. Gastrointest Endosc 2016;84:1034-9.

7 Han P, Che D, Pallav K, et al. Models of the cutting edge geometry of medical needles with applications to needle design. Int J Mech Sci 2012;65:157-67.

8 Sato $\mathrm{N}$, Cheng XB, Kohi S, et al. Targeting hyaluronan for the treatment of pancreatic ductal adenocarcinoma. Acta Pharm Sin B 2016;6:101-5.

9 Jacobetz MA, Chan DS, Neesse A, et al. Hyaluronan impairs vascular function and drug delivery in a mouse model of pancreatic cancer. Gut 2013;62:112-20.
10 Bournet B, Muscari F, Buscail C, et al. KRAS G12D mutation subtype is a

prognostic factor for advanced pancreatic adenocarcinoma. Clin Trans/ Gastroenterol 2016;7:e157.

11 Kopelman Y, Marmor S, Ashkenazi I, et al. Value of EUS-FNA cytological preparations compared with cell block sections in the diagnosis of pancreatic solid tumours. Cytopathology 2011:22:174-8.

12 Varadarajulu S, Bang JY, Holt BA, et al. The 25-gauge EUS-FNA needle: good for on-site but poor for off-site evaluation? Results of a randomized trial. Gastrointest Endosc 2014;80:1056-63. 